\title{
Beware Cold Agglutinins in Organ Donors! Ex Vivo Lung Perfusion From an Uncontrolled Donation After Circulatory-Determination-of- Death Donor With a Cold Agglutinin: A Case Report
}

\author{
A. Venkataraman ${ }^{a}$, J.W. Blackwell ${ }^{a}$, W.K. Funkhouser ${ }^{b}$, K.R. Birchard ${ }^{c}$, S.E. Beamer ${ }^{a}$, W.T. Simmons ${ }^{a}$, \\ S.H. Randell ${ }^{d}$, and T.M. Egan ${ }^{\mathrm{a}, *}$ \\ ${ }^{a}$ Department of Surgery, Division of Cardiothoracic Surgery, University of North Carolina, Chapel Hill, North Carolina; ${ }^{\circ}$ Department of \\ Pathology and Laboratory Medicine, University of North Carolina, Chapel Hill, North Carolina; 'Department of Radiology, University of \\ North Carolina, Chapel Hill, North Carolina; and dDepartment of Cell Biology and Physiology, University of North Carolina, Chapel Hill, \\ North Carolina
}

\begin{abstract}
Background. We began to recover lungs from uncontrolled donation after circulatory determination of death to assess for transplant suitability by means of ex vivo lung perfusion (EVLP) and computerized tomographic (CT) scan. Our first case had a cold agglutinin with an interesting outcome.

Case report. A 60-year-old man collapsed at home and was pronounced dead by Emergency Medical Services personnel. Next-of-kin consented to lung retrieval, and the decedent was ventilated and transported. Lungs were flushed with cold Perfadex, removed, and stored cold. The lungs did not flush well. Medical history revealed a recent hemolytic anemia and a known cold agglutinin. Warm nonventilated ischemia time was 51 minutes. $\mathrm{O}_{2}$-ventilated ischemia time was 141 minutes. Total cold ischemia time was 6.5 hours. At cannulation for EVLP, established clots were retrieved from both pulmonary arteries. At initiation of EVLP with Steen solution, tiny red aggregates were observed initially. With warming, the aggregates disappeared and the perfusate became red. After 1 hour, EVLP was stopped because of florid pulmonary edema. The lungs were cooled to $20^{\circ} \mathrm{C}$; tiny red aggregates formed again in the perfusate. Ex vivo CT scan showed areas of pulmonary edema and a pyramidal right middle lobe opacity. Dissection showed multiple pulmonary emboli-the likely cause of death. However, histology showed agglutinated red blood cells in the microvasculature in pre- and post-EVLP biopsies, which may have contributed to inadequate parenchymal preservation.
\end{abstract}

Conclusions. Organ donors with cold agglutinins may not be suitable owing to the impact of hypothermic preservation.

$\mathbf{L}$ UNG transplantation (LT) is a successful therapy to improve survival and quality of life for patients with terminal respiratory diseases. This has led to increased demand for LT. Although lung disease is the 3rd leading cause of death in the United States [1], only 2,000 lung transplantations were performed annually for the past 2 years [2]. Only $\sim 20 \%$ of lungs from brain-dead donors are used for LT. The shortage of lung donors has led to strict listing criteria [3], using marginal donors, and "reconditioning" some unsuitable lungs with ex vivo lung perfusion (EVLP) $[4,5]$. In the United States, some lungs have been transplanted after recovery from controlled donation after

Funding: National Institutes of Health (grant RC2HL101641).

*Address correspondence to Thomas M. Egan, MD, MSc, Division of Cardiothoracic Surgery, University of North Carolina at Chapel Hill, 3040 Burnett-Womack Bldg., CB \#7065, Chapel Hill, NC 27599-7065, USA. E-mail: Ltxtme@med.unc.edu 

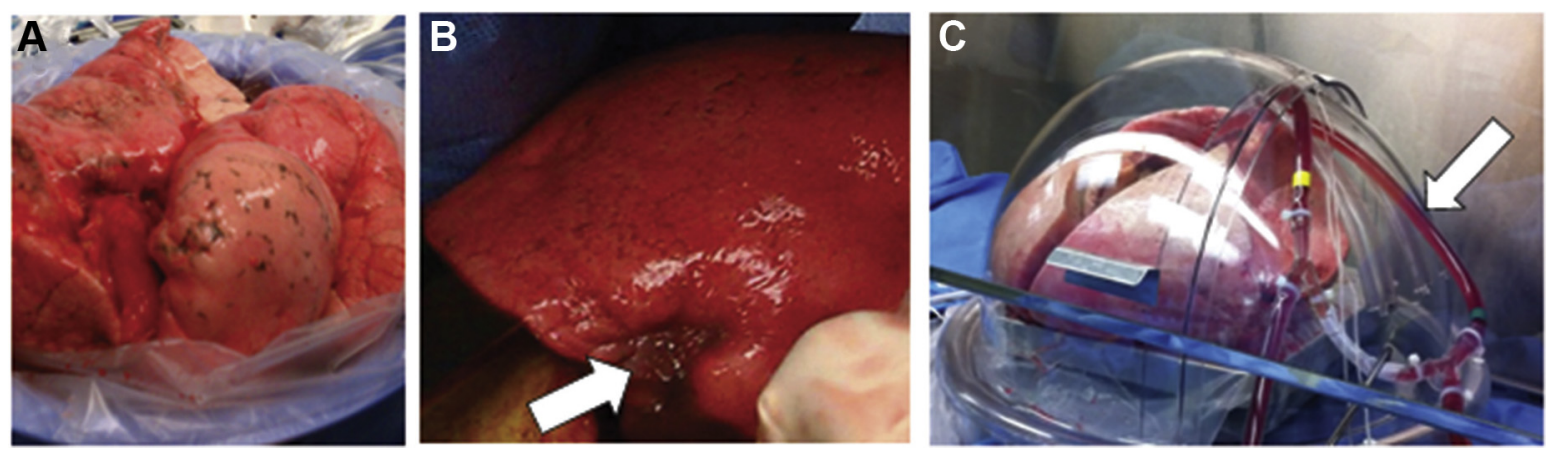

Fig 1. (A) Lungs blanched suboptimally with the use of Perfadex flush. (B) Visible indurated wedge-shaped pulmonary infarct (arrow). (C) Lungs in EVLP circuit at $37^{\circ} \mathrm{C}$, demonstrating perfusate that was much redder than usual (arrow).

circulatory determination of death donors (cDCDDs) [6]. There is growing experience outside the United States with LT from uDCDDs [7-9]. uDCDDs are victims of sudden death that occurs outside of hospital or in a hospital (formerly known as Maastricht category 1 and 2, respectively, non-heart-beating donors) [10]. One of us showed that lungs from uDCDDs could be recovered hours after death and function well after transplantation [11,12] and was the principal investigator of a National Institutes of Health-funded clinical trial (NCT01615484) to determine the safety of transplanting uDCDD lungs after assessment by means of EVLP and ex vivo computerized tomographic (CT) scan. With Food and Drug Administration and Institutional Review Board approval, we began to procure lungs from uDCDDs. Our first uDCDD donor had a cold agglutinin, which likely contributed to poor lung function.

\section{CASE REPORT}

A 60-year-old white man had a witnessed collapse at home. Cardiopulmonary resuscitation (CPR) was initiated immediately, and Emergency Medical Services (EMS) took over CPR 6 minutes after being called. After 21 additional minutes of CPR, EMS personnel declared death. The decedent's spouse was present. EMS contacted Carolina Donor Services (CDS), our organ procurement organization. After some screening medical questions (history of cancer, lung disease, inhaler use, smoking, infections), CDS obtained consent for lung recovery from his next-of-kin (NOK). EMS personnel began ventilation 51 minutes after death was declared. The decedent was transported to University of North Carolina (UNC) Hospitals for lung recovery. Meanwhile, CDS staff obtained a detailed medical and social history from the NOK, as is done for every organ donor. The decedent was a lifelong nonsmoker who was investigated a few weeks earlier for fatigue and found to have hemolytic anemia, a cold agglutinin, and negative serologies for autoimmune diseases. He had a recent history of shortness of breath on exertion, and 3 days before his death he had received a transfusion for low hemoglobin.

Lungs were flushed antegrade and retrograde with cold Perfadex 2 hours and 21 minutes after ventilation began. Prostin and heparin were placed in the 1st liter. However, the lungs did not blanch well with the use of cold Perfadex flush (Fig 1A). A visible pyramidal indurated purple lesion seen in the right middle lobe was consistent with a pulmonary infarct (Fig 1B). Blood was sent for typing and serologies. The lungs were removed and stored in cold Perfadex. EVLP was started according to the University of Toronto protocol [5] with the use of XVIVO hardware and Steen solution. EVLP was started at a time when serology results were anticipated to be back before completion of 4 hours of EVLP: 6 hours 21 minutes after initiation of cold storage. Inspection of the pulmonary artery (PA) at cannulation revealed organized thrombi in both left and right PAs. The thrombi were extracted before the start of EVLP. Retrograde perfusion with the use of Steen solution resulted in tiny bright red clumps in the effluent. Antegrade EVLP was then started at low flow, and tiny red aggregates were observed in the EVLP circuit.

As the perfusate temperature was increased to $37^{\circ} \mathrm{C}$, the aggregates disappeared and the perfusate was much more red than usual (Fig 1C). Once $40 \%$ of the predicted cardiac output was achieved (2.1 L/min), mean PA pressure was $25 \mathrm{~mm} \mathrm{Hg}$, and florid pulmonary edema appeared in the endotracheal tube and was confirmed

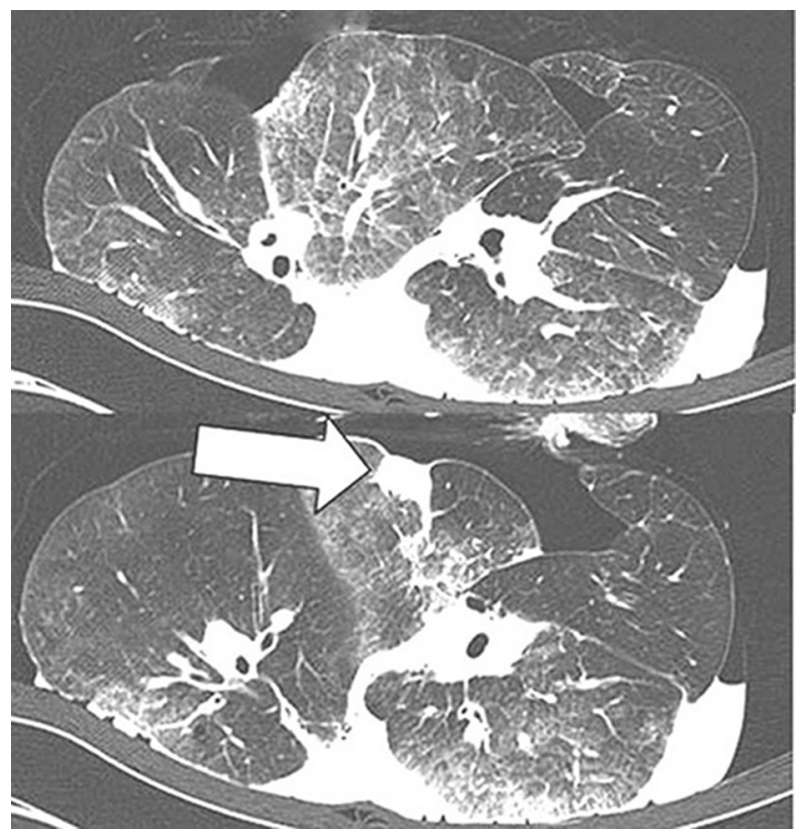

Fig 2. Ex vivo computerized tomography, showing patchy mild dependent pulmonary edema and wedge-shaped opacity consistent with a pulmonary infarct (arrow). 
Fig 3. (A and B) Clots in small and mid-sized pulmonary arteries (PAs) and red blood cells (RBCs) in small blood vessels in pre-EVLP biopsy (after Perfadex flush). (C and D) RBCs in large PA (probably agglutinated RBCs) and in alveolar capillaries (after 2nd cold Perfadex flush).

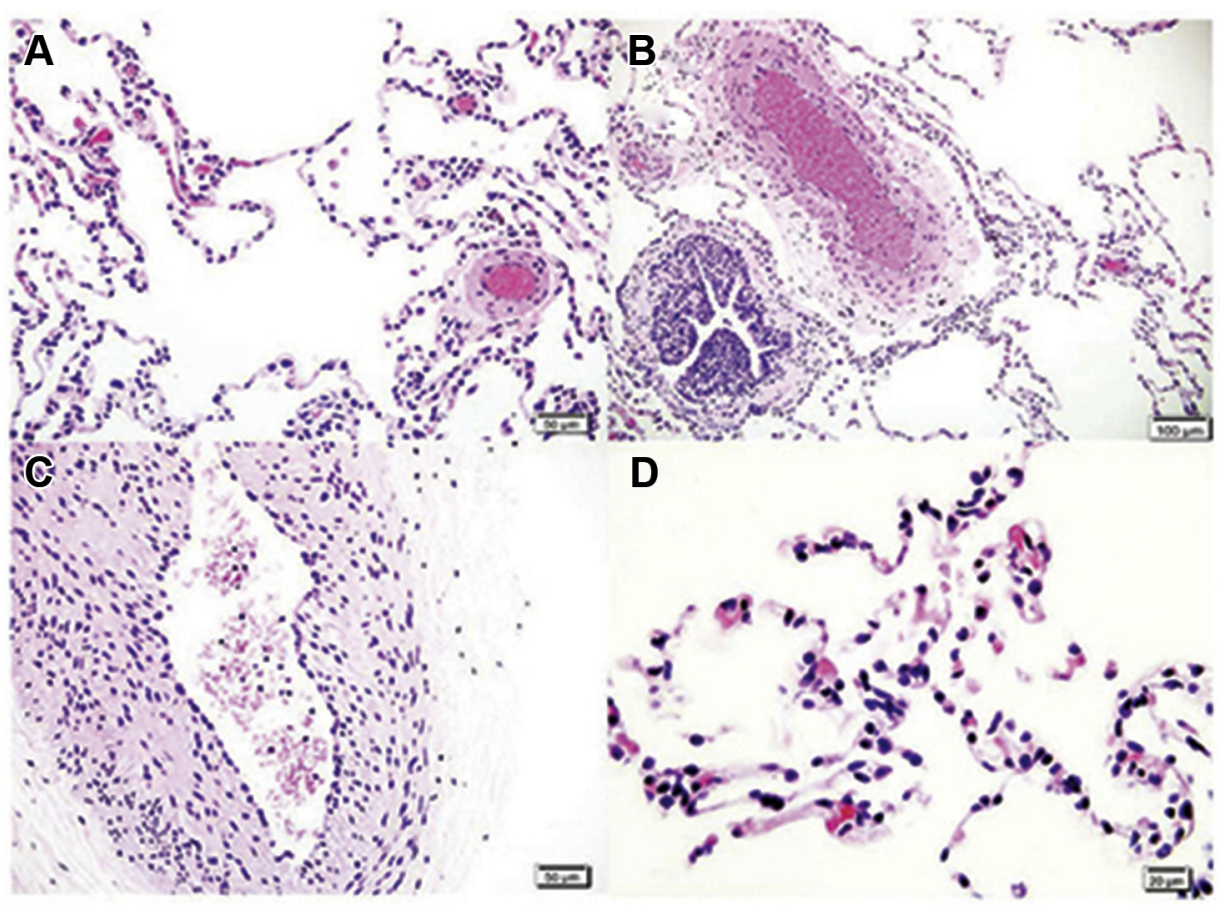

by bronchoscopy. The tidal volume was increased to $920 \mathrm{~mL}(10$ $\mathrm{mL} / \mathrm{kg}$ ) and $5 \mathrm{~cm} \mathrm{H}_{2} \mathrm{O}$ positive end expiratory pressure for lung assessment. The inflow $\mathrm{pO}_{2}$ was $30 \mathrm{~mm} \mathrm{Hg}$ while the left atrial $\mathrm{pO}_{2}$ was $456 \mathrm{~mm} \mathrm{Hg}$. The airway pressure was $24 \mathrm{~cm} \mathrm{H}_{2} \mathrm{O}$ peak and $9 \mathrm{~cm}$ $\mathrm{H}_{2} \mathrm{O}$ mean. Owing to florid pulmonary edema, with fluid accumulating in the airway circuit tubing, EVLP was terminated. The circuit perfusate was cooled, and the tiny red aggregates began to reappear in the circuit. Once circuit temperature reached $20^{\circ} \mathrm{C}$, the inflated lungs were flushed antegrade with $2 \mathrm{~L}$ cold Perfadex. The lungs then underwent an ex vivo CT scan.

Despite the extent of pulmonary edema, ex vivo CT scan of the donor lungs demonstrated only patchy mild pulmonary edema and a wedge-shaped opacity in the right middle lobe consistent with an infarct (Fig 2). The lungs were provided to the UNC Cystic Fibrosis Center cell culture core for cell recovery. Dissection of the pulmonary arteries revealed clots in several subsegmental branches of the pulmonary vasculature. Histologic examination of the preEVLP lung biopsy demonstrated clots in small and mid-sized PAs and red blood cells (RBCs) in small blood vessels. The post-EVLP biopsy showed RBCs in the large PA and in alveolar capillaries, probably signifying agglutinated RBCs (Fig 3).

\section{DISCUSSION}

This donor died from multiple pulmonary emboli, as suspected initially from lung recovery and cannulation for EVLP and subsequently confirmed by means of lung dissection after EVLP. Pulmonary emboli before his lethal event (one causing an infarct) were the likely cause of his symptoms of dyspnea for 3 days before his death. The pulmonary emboli and the presence of a cold agglutinin likely prevented adequate hypothermic preservation, thereby leading to florid pulmonary edema once perfusion was established in the EVLP circuit.
Despite obvious pulmonary edema, airway pressure was only mildly elevated and $\mathrm{pO}_{2}$ during EVLP was acceptable. Ex vivo CT scan demonstrated some pulmonary edema, but it was less than anticipated (Fig 2). However, EVLP allows for multiple methods of evaluation, including direct observation and bronchoscopy. In an earlier experience with EVLP of lungs recovered from brain-dead donors whose lungs were unsuitable for transplantation, our radiologist thought that a CT scan was much better than plain radiographs for demonstrating lung parenchymal abnormalities [13].

Autoimmune hemolytic anemia associated with cold agglutinins is a rare disorder. Cold agglutinins have also been observed in association with other conditions, including malignancies [14]. Similar particulate aggregates were reported by Patel et al during cardiopulmonary bypass when circuit temperature reached $32^{\circ} \mathrm{C}$ [15]. Guidelines for management of patients found to have cold agglutinins during cardiac surgery have been suggested but are based on small numbers [16]. We are unaware of any reports of attempted organ recovery in a donor with a known cold agglutinin. Although this is a rare condition, hypothermic perfusion preservation induced RBC agglutination and almost certainly contributed to impaired preservation. Therefore, patients with cold agglutinins are not suitable organ donors, because it is likely that agglutinated RBCs (Fig 3) would hamper adequate preservation.

\section{ACKNOWLEDGMENTS}

The authors appreciate editorial assistance from Margaret Alford Cloud (UNC Division of Cardiothoracic Surgery) and the dedication of Wake County EMS staff and CDS personnel. XVIVO provided Steen solution, Perfadex, cannulae, and organ chambers. Conmed/ Linvatec and Instrumentation Labs provided donations in kind. 


\section{REFERENCES}

[1] Kochanek KD, Xu JQ, Murphy SL, Minino AM, Kung HC. Deaths: Preliminary data for 2009. National vital statistics reports. Hyattsville, MD: National Center for Health Statistics; 2011. Available at: http://www.cdc.gov/nchs/data/nvsr/nvsr59/nvsr59_04. pdf. Accessed Jan. 31, 2017.

[2] Organ Procurement and Transplantation Network. Available at: https://optn.transplant.hrsa.gov. Accessed Jan.31, 2017.

[3] Weill D, Benden C, Corris PA, et al. A consensus document for the selection of lung transplant candidates: 2014-an update from the Pulmonary Transplantation Council of the International Society for Heart and Lung Transplantation. J Heart Lung Transplant 2015;34:1-15.

[4] Ingemansson R, Eyjolfsson A, Mared L, et al. Clinical transplantation of initially rejected donor lungs after reconditioning ex vivo. Ann Thorac Surg 2009;87:255-60.

[5] Cypel M, Yeung JC, Liu M, et al. Normothermic ex vivo lung perfusion in clinical lung transplantation. N Engl J Med 2011;364 1431-40.

[6] Mooney JJ, Hedlin H, Mohabir PK, et al. Lung quality and utilization in controlled donation after circulatory determination of death within the United States. Am J Transplant 2016;16:1207-15.

[7] Steen S, Sjoberg T, Pierre L, Liao Q, Eriksson L, Algotsson L. Transplantation of lungs from a nonheart beating donor. Lancet 2001;357:825-9.

[8] Gomez-de-Antonio D, Campo-Canaveral JL, Crowley S, et al. Clinical lung transplantation from uncontrolled nonheartbeating donors revisited. J Heart Lung Transplant 2012;31:349-53.
[9] Valenza F, Citerio G, Palleschi A, et al. Successful transplantation of lungs from an uncontrolled donor after circulatory death preserved in situ by alveolar recruitment maneuvers and assessed by ex-vivo lung perfusion. Am J Transplant 2016;16: $1312-8$

[10] Kootstra G, Daemen JH, Ooen AP. Categories of nonheart-beating donors. Transplant Proc 1995;27:2893-4.

[11] Egan TM, Lambert Jr CJ, Reddick RL, Ulicny Jr KS, Keagy BA, Wilcox BR. A strategy to increase the donor pool: the use of cadaver lungs for transplantation. Ann Thorac Surg 1991;52: $1113-21$.

[12] Ulicny Jr KS, Egan TM, Lambert Jr CJ, Reddick RL, Wilcox BR. Cadaver lung donors: effect of preharvest ventilation on graft function. Ann Thorac Surg 1993;55:1185-91.

[13] Egan TM, Haithcock JA, Nicotra WA, et al. Ex vivo evaluation of human lungs for transplant suitability. Ann Thorac Surg 2006;81:1205-13.

[14] Berentsen S, Tjonnfjord GE. Diagnosis and treatment of cold agglutinin mediated autoimmune hemolytic anemia. Blood Rev 2012;26:107-15.

[15] Patel PA, Ghadimi K, Coetzee E, et al. Incidental cold agglutinins in cardiac surgery: intraoperative surprises and team-based problem-solving strategies during cardiopulmonary bypass. J Cardiothorac Vasc Anesth. Published online June 18, 2016.

[16] Barbara DW, Mauermann WJ, Neal JR, Abel MD, Schaff HV, Winters JL. Cold agglutinins in patients undergoing cardiac surgery requiring cardiopulmonary bypass. J Thorac Cardiovasc Surg 2013;146:668-80. 